\title{
Research on the Numerical Simulation of Sleeper in the Pipeline Global Buckling Controlling Practice
}

\author{
Wen-Bin LIU ${ }^{\mathrm{a}}$, Ai-Min LIU \\ CCCC Tianjin Port Engineering Institute Co., Ltd. Tianjin, China \\ aliuwenbin3943@163.com, ${ }^{b}$ liuaimin1987@163.com
}

\begin{abstract}
This paper analyzed the lateral buckling of pipelines located in Western Africa with ABAQUS software. The application of sleepers in practice is explored to guide the pipeline buckling controlling design.
\end{abstract}

\section{Introduction}

High temperature and pressure are applied on the submarine pipeline to ensure the fluency of oil. The high temperature and pressure load causes large stress in the cross-section of pipeline, and leading to large lateral global displacement of deep-sea pipeline. Uncontrolled lateral global buckling causes large deformation of pipeline, threatening the safety of pipeline systems.

In engineering practice, there are two kinds of method to deal with this uncontrolled global buckling: preventing method and triggering method. The preventing method usually includes: (1) pre-cooling the oil to reduce the additional stress; (2) using pipe-in-pipe or increasing the number of tube to enhance the flexural rigidity; (3) installing traction device to introduce pre-tension into the pipelines. The triggering method is mainly implemented by: (1) placing sleepers in design location; (2) snakedlaying pipelines; (3) adding distributed buoyance devices on the pipelines. Comparing to the preventing method, the triggering method reduce the cost a lot, but requiring more delicate design. In addition, with the increasing operation water depth, the triggering method becomes more feasible for implementing in practice. The triggering method becomes an advanced research hotspot.

This paper analyzed the lateral buckling of pipelines located in Western Africa with ABAQUS software. The application of sleepers in practice is explored to guide the pipeline buckling controlling design.

\section{The engineering Case}

The case locates in the Western Africa, and the working water depth is $1150-1500 \mathrm{~m}$. The specific data about the pipeline system is shown in Table 1.

The properties of surface soil determine the postbuckling pipeline's deformation. The property of surface soil is usually unstable, and to obtain certain strength of surface soil is difficult. In order to ensure the accurate of calculating results, the upper-limit value, lower-limit value and the mid-value are considered in analysis. The relative parameters of surface soil are shown in Table 2.

Table 1. Pipeline system's design parameters

\begin{tabular}{|c|c|c|c|c|c|c|c|c|}
\hline $\begin{array}{c}\text { Outer } \\
\text { diameters }\end{array}$ & $\begin{array}{c}\text { Wall } \\
\text { thickness }\end{array}$ & $\begin{array}{c}\text { Modulus of } \\
\text { elasticity }\end{array}$ & $\begin{array}{c}\text { Steel's } \\
\text { density }\end{array}$ & \multicolumn{2}{c}{$\begin{array}{c}\text { Thermal } \\
\text { expansion } \\
\text { coefficient }\end{array}$} & $\begin{array}{c}\text { Poisson's } \\
\text { ratio }\end{array}$ & $\begin{array}{c}\text { Soil resistance } \\
\text { coefficient }\end{array}$ & $\begin{array}{c}\text { Steel's yield } \\
\text { strength }\end{array}$ \\
\hline$D / \mathrm{mm}$ & $t / \mathrm{mm}$ & $E / \mathrm{GPa}$ & $\rho_{\mathrm{S}} / \mathrm{kg} \cdot \mathrm{m}^{-3}$ & $\alpha /{ }^{\circ} \mathrm{C}^{-1}$ & $v$ & $\varphi$ & $\sigma_{\mathrm{s}} / \mathrm{MPa}$ \\
\hline 323.9 & 19.1 & 206 & 7850 & $1.1 \times 10^{-5}$ & 0.3 & 0.4 & 520 \\
\hline
\end{tabular}

Table 2 Strength of surface soil

\begin{tabular}{|c|c|c|c|}
\hline $\begin{array}{c}\text { Depth } \\
/ \mathrm{m}\end{array}$ & $\begin{array}{c}\text { Lower-limit value } \\
\mathrm{Su}(\mathrm{kPa})\end{array}$ & $\begin{array}{c}\text { Mid-value } \\
\mathrm{Su}(\mathrm{kPa})\end{array}$ & $\begin{array}{c}\text { Upper-limit value } \\
\text { Su }(\mathrm{kPa})\end{array}$ \\
\hline 0 & 0.5 & 0.75 & 1 \\
\hline 0.15 & 1 & 2 & 3 \\
\hline 0.7 & 8 & 11 & 15 \\
\hline 0.9 & 8 & 11 & 15 \\
\hline
\end{tabular}


The sleepers are placed under the pipelines in several preset location in this case to trigger the lateral buckling. The sleeper is a large diameter $(1 \mathrm{~m})$ solid tube, showing in the Figure 1.
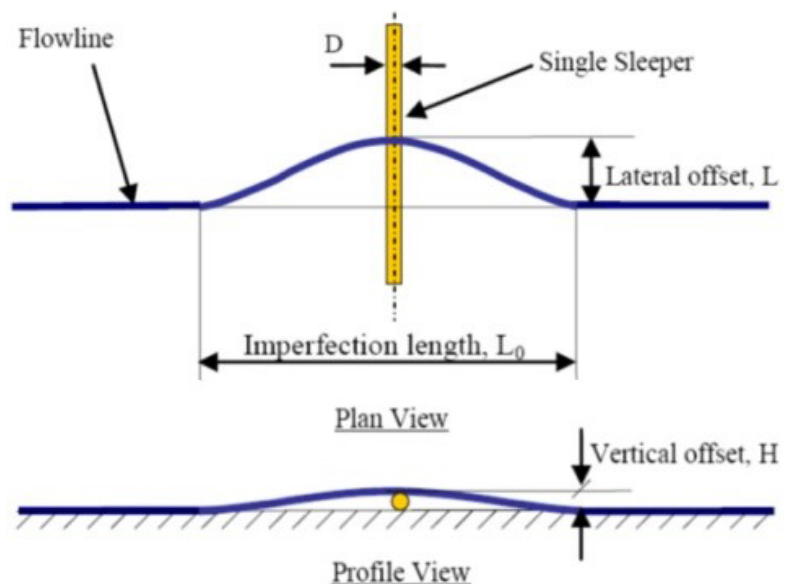

Profile View
The symbol $\mathrm{H}$ is the vertical height of the sleeper. The symbol $\mathrm{L}$ represents the lateral offset of pipeline, and L0 represents the length for the pipeline segment untouching the seabed.

\section{Numerical Simulation}

For analyzing the excepted effect of the sleeper, the pipeline is simulated in the software ABAQUS. The pipeline is modeled with the S4R element. The element in the pipeline segment within $200 \mathrm{~m}$ of the sleeper is 0.5 long, and the element in other segment is $5 \mathrm{~m}$ long. The total length of pipeline is $7400 \mathrm{~m}$, including 2 sleepers located at 2 different places. A part of finite element analysis model is shown in Figure 2.

Figure 1. Sketch of a pipeline laying on a sleeper

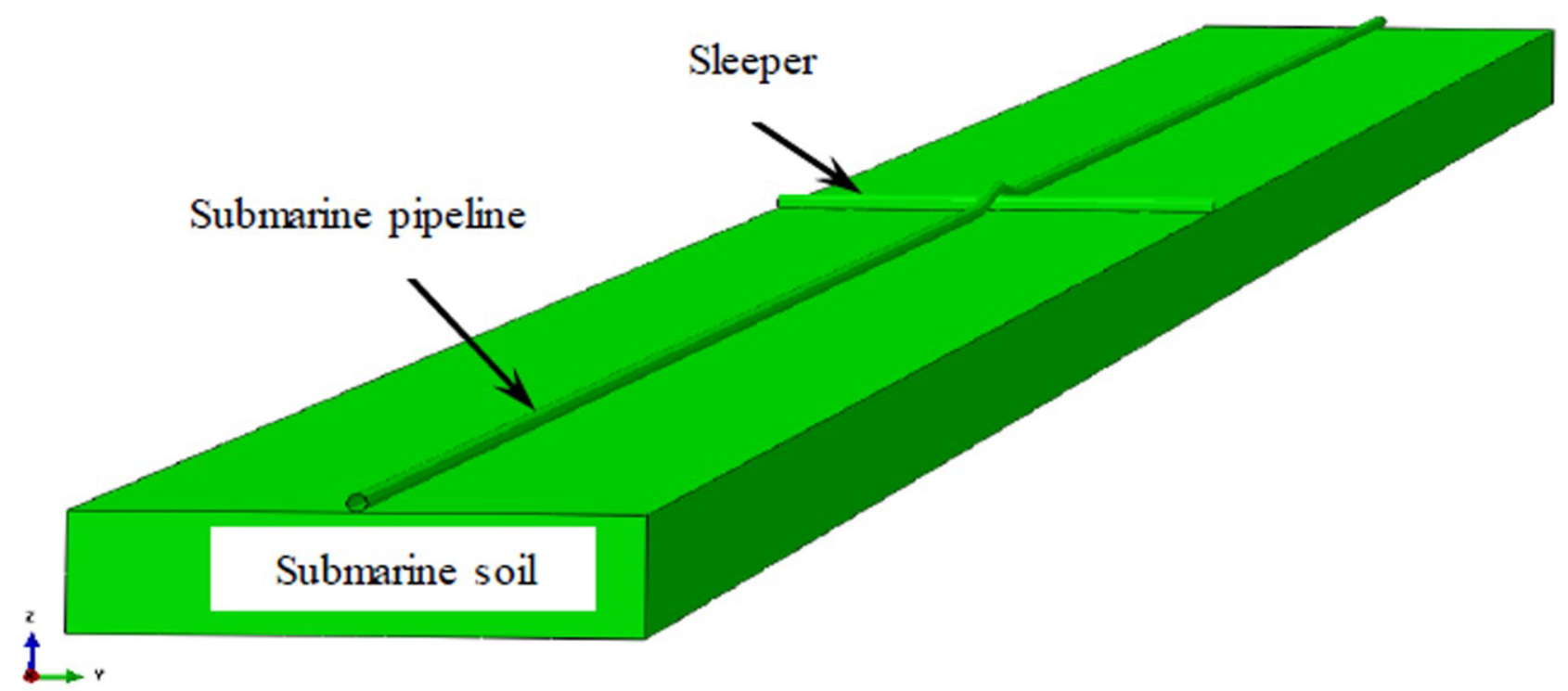

Figure 2. A part of finite element analysis model

The entry endpoint of the pipeline can move freely in axial direction. The exit endpoint of the pipeline can expand freely, but the shrinking movement of the exit endpoint is restricted by an anchor chain. The restriction of the anchor chain is simulated as a spring. The relationship between restricting force and displacement is displayed in Figure 3. The maximum tension of the anchor chain is $1 \mathrm{MN}$, and the corresponding extension length is $0.12 \mathrm{~m}$.

The lateral friction coefficient between pipeline and soil is 0.9 when the lateral displacement is no more than $25 \mathrm{~mm}$. The lateral friction coefficient is 0.7 when the lateral displacement is larger than $25 \mathrm{~mm}$. This dynamical soil resistance is simulated using a subroutine VFRIC. The calculating result is displayed in Figure 4.

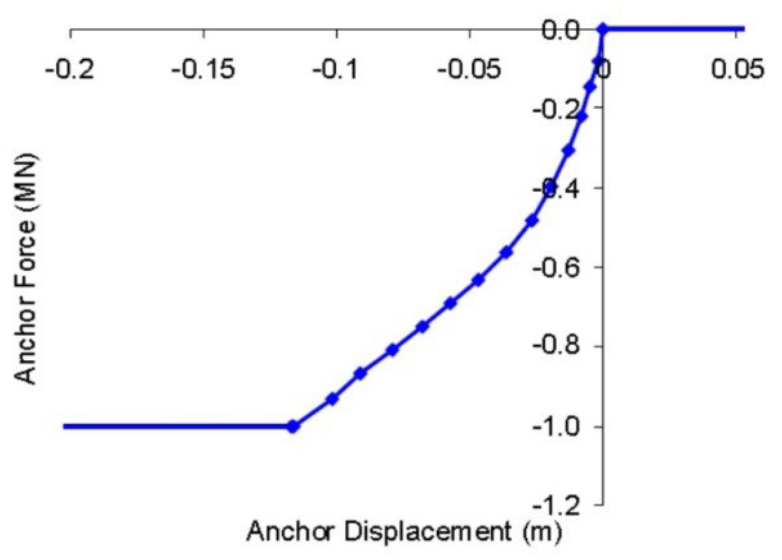

Figure 3 The relationship between anchor force and displacemen 


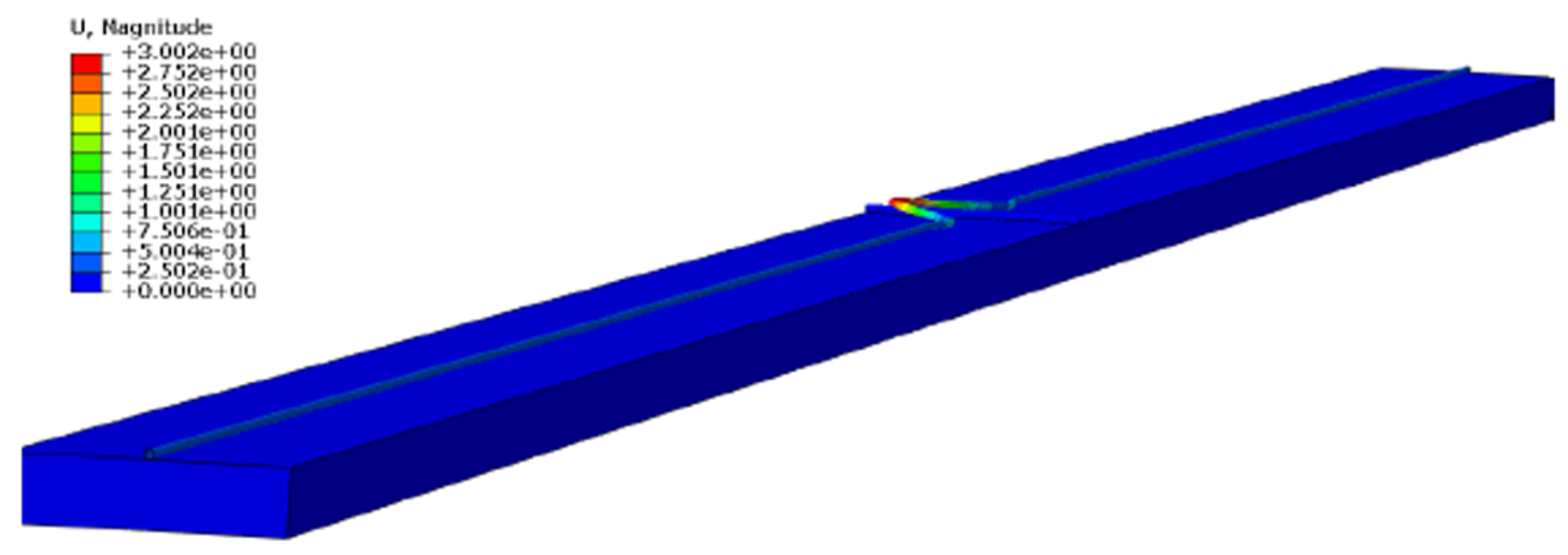
$r$

(a) The lateral buckling of the pipeline with a sleeper

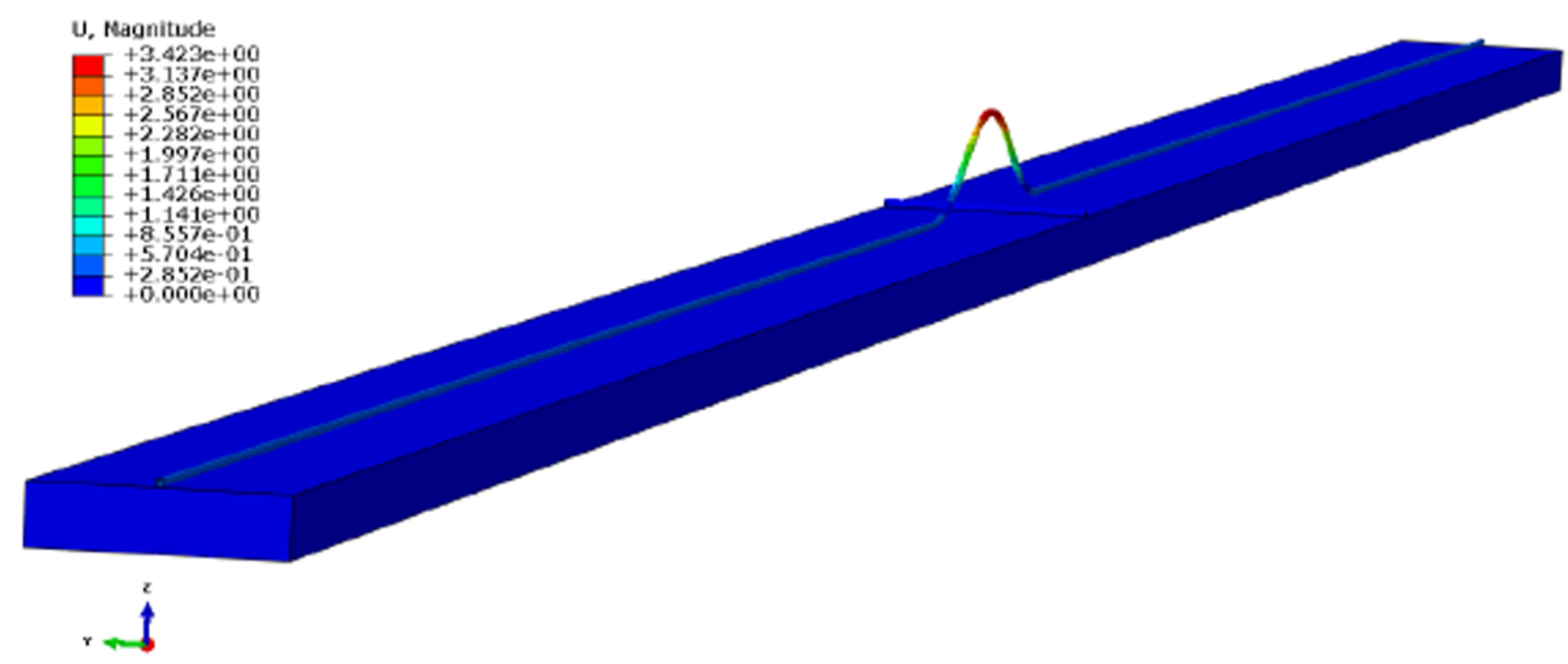

(b) The vertical buckling of the pipeline with a sleeper

Figure 4. Simulation results

From the Figure 4 (a), we can see that the critical lateral buckling force is less than the critical vertical buckling force. This is because the vertical buckling needs to overcome the self-weight of the pipeline. The pipeline laid on the even seabed is easier to experience lateral buckling. But with the lightening of pipeline's selfweight, vertical buckling can happen on the light segment laid on the sleepers. The post-buckling pipeline which suffers vertical buckling rises up, separating with the seabed in operation. After the pipeline shut down, and this rising segment of pipeline drops down, touching the seabed and the sleeper again. This rising and dropping reciprocating movement causes pipeline vibration, influencing the safety of pipelines.

\section{Conclusion}

The pipeline laid on sleepers is easier to suffer lateral buckling rather than vertical buckling. While with the lightening of pipeline's self-weight, the vertical buckling becomes possible. The light pipeline will suffer vertical buckling first, and then experience lateral buckling.

\section{Acknowledgment}

The authors are grateful for the support provided by the Natural Science Foundation of Tianjin (16JCQNJC07200), Key Laboratory of Port Geotechnical Engineering of 
Tianjin and Key Laboratory of Port Geotechnical Engineering, Ministry of Communications, PRC.

\section{References}

1. Bruton D, Carr M, Crawford M, et al. (2005) "The safe design of hot on-bottom pipelines with lateral buckling using the design guideline developed by the safebuck joint industry project" Proceedings of the Deep Offshore Technology Conference, Vitoria, Espirito Santo, Brazil.

2. Bruton D, Carr M, White D, et al. (2007) "The influence of Pipe-Soil interaction on Lateral Buckling and walking of pipelines- The SAFEBUCK JIP" Proc. International Offshore Investigation and Geotechnics (OSIG) Conference.

3. Bruton D, Bolton M, Carr M, et al. (2008) "Pipe-soil interaction with flowlines during lateral buckling and pipeline walking - The SAFEBUCK JIP" Offshore Technology Conference.

4. Chee K Y and Walker A. (2011). "Assessment of Numerical Modelling of Pipeline Lateral Buckling." Proc., Int. Symp. on Lateral Buckling, Australia.
5. Hong ZH, Liu R, Liu WB, Yan SW. (2015a) “A lateral global buckling failure envelope for a high temperature and high pressure (HT/HP) submarine pipeline.” Applied Ocean Research, 51:117-128.

6. Hong ZH, Liu R, Liu WB, Yan SW. (2015b) "Study on lateral buckling characteristics of a submarine pipeline with a single arch symmetric initial imperfection" Ocean engineering, 108: 21-32.

7. Junior E P, da Rocha R S, da Costa Á M, et al. (2004) "Experimental Tests and Numerical Simulation in a Reduced Model in a Pipeline With ZIG-ZAG Geometry: A Parametric Study" International Pipeline Conference. American Society of Mechanical Engineers, 399-407.

8. Konuk I, Yu S. Continuum (2007) "FE modeling of lateral buckling: study of soil effects" 26th International Conference on Offshore Mechanics and Arctic Engineering. American Society of Mechanical Engineers, 347-354.

9. Liu R, Liu W, Wu X, et al. (2014) "Global lateral buckling analysis of idealized subsea pipelines" Journal of Central South University, 21: 416-427. 